\title{
Creatine Kinase BB Measurement
}

National Cancer Institute

\section{Source}

National Cancer Institute. Creatine Kinase BB Measurement. NCI Thesaurus. Code C64490.

A quantitative measurement of the amount of homozygous B-type creatine kinase present in a sample. 